Gut, 1986, 27, 1204-1209

\title{
Influence of the degree of liver failure on systemic and splanchnic haemodynamics and on response to propranolol in patients with cirrhosis
}

\author{
A BRAillon, PCALES, D VALLA, D GAUDY, PGEOFFROY, AND D LEBREC \\ From the Unité de Recherches de Physiopathologie Hépatique (INSERM U 24) Hôpital Beaujon, Clichy, \\ France
}

SUMMARY Systemic and splanchnic haemodynamics were studied in patients with cirrhosis who had been classified in three groups (A, B, and C) according to the degree of liver failure (modified Pugh's classification). In patients of group A, cardiac index was significantly lower than that of group $\mathrm{C}$ and systemic vascular resistance was higher, but not significantly so, than that of patients with liver failure. Wedged hepatic venous pressure was significantly lower in the former group than in the latter. In patients in group B, corresponding values fell between those of groups $\mathrm{A}$ and $\mathrm{C}$. Azygos blood flow averaged $0.477 \pm 0.242 \mathrm{l} / \mathrm{min}$ (mean $\pm \mathrm{SD}$ ) in group $\mathrm{A}$ and it was significantly lower than in groups B and C (0.642 $\pm(0.224$ and $1.061 \pm() .476 \mathrm{1} / \mathrm{min}$, respectively). In the three groups, acute administration of propranolol induced statistically significant changes in systemic and splanchnic haemodynamics. In patients of group $\mathrm{C}$ but not of group $\mathrm{B}$, the mean value of azygos blood flow after propranolol remained significantly higher than in group A. Moreover, the fraction of azygos blood flow to cardiac output decreased in groups A and B while slightly increased in group C. This study shows that in patients with cirrhosis, the degree of liver failure may be a determinant for the haemodynamic responses to drugs acting on portal hypertension.

In patients with cirrhosis, the changes in systemic circulation have been well characterised, ${ }^{Y-3}$ and there are indications that the magnitude of systemic haemodynamic changes is related both to development of portal hypertension ${ }^{4}$ and to impairment of liver function. ${ }^{35}$ The relationship between alterations in splanchnic circulation and degree of liver failure, however, has received less attention. Such a relationship would have therapeutic implications. For example, it has been reported that the effects of propranolol on hepatic venous pressure gradient would be less marked in patients with end stage liver disease, with the consequence that propranolol might be less efficient in the prevention of recurrent gastrointestinal bleeding in patients with advanced liver failure than in patients in good condition."

This study is intended first to determine whether changes in systemic and splanchnic haemodynamics are related with the stage of liver disease and

Address for correspondence: Dr D I cebrec. INSI:RM U 24, Hopital Beaujon. 92118 Clichy. France.

Received for publication 7 February 1986 second, to evaluate the haemodynamic effects of propranolol according to the degree of liver failure in patients with cirrhosis.

\section{Methods}

PATIENTS

Fifty patients with histologically proven cirrhosis admitted for hepatomegaly and/or ruptured oesophageal varices and/or ascites, and/or jaundice were investigated (Table 1). According to a modified Pugh's classification ${ }^{7}$ - not including prolongation of the prothrombin time - those patients whose score totalled four or five were considered to be in good condition (class A), six to eight moderate (class B), and patients with 9-12 were considered to be in poor condition (class $\mathrm{C}$ ). Accordingly, there were 16 class A (seven had four points and nine had five), 18 class B (three had six points, seven had seven and eight had eight) and 16 class $C$ patients (nine had nine points and seven had 10). Causes of cirrhosis, clinical characteristics and laboratory data are summarised in Table 1. All patients gave oral informed consent 
Table 1 Clinical characteristics and laboratory values in patients with cirrhosis according to the degree of liver failure*

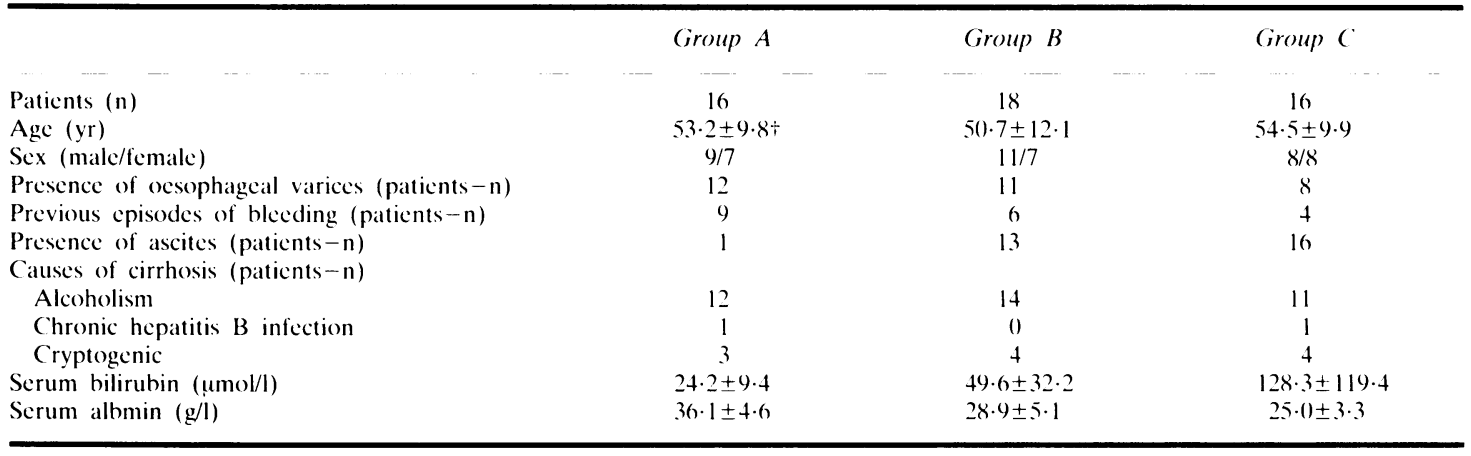

*According to a modified Pugh's classification (see Method section). $\rightarrow$ Mean \pm SD.

to the investigation described below which was done at the same time as a transvenous liver biopsy, ${ }^{\circ}$ or as a part of the evaluation of portal hypertension, (this investigation is routinely carried out in this Liver Unit). In patients admitted for ruptured oesophageal varices, this haemodynamic investigation was done eight to 15 days after haemorrhage when the circulatory condition returned to a steady state. They did not receive any drugs, particularly no $\beta$-blocking agent. Patients admitted for ascites received diuretics for one to two weeks. Paracentesis was not undertaken in these patients. Moreover, in all patients heart rate and mean arterial pressure were stable during the week preceding the haemodynamic investigation. In patients with alcoholic cirrhosis, no clinical, electrocardiographic or radiologic manifestations of alcoholic cardiomyopathy were observed. The results of this haemodynamic assessment are thereafter referred to as baseline haemodynamic values. In 24 of these 50 patients, the haemodynamic study was done before and 15 minutes after intravenous administration of $15 \mathrm{mg}$ propranolol. The dose of $15 \mathrm{mg}$, a large dose, slowly and carefully injected, was used in order to saturate $\beta$-adrenoceptors in all patients. A part of the results has been previously reported. ${ }^{9}$

The haemodynamic studies were carried out in patients lying in the supine position after an overnight fast; they were sedated with meperidine hydrochloride, $50 \mathrm{mg}$, intramuscularly. Mean arterial pressure was measured with an external sphygmomanometer (Dinamap, Critikon, Tampa, FL, USA), using electronic pressure integration. After local anaesthesia, a vessel dilatator with a polypropylene sheath (Desilets, Vygon, Ecouen, France) was inserted percutaneously into the lumen of the right internal jugular vein for successive introduction of different catheters. Cardiac output was determined in triplicate by the thermodilution technique with a Swan-Ganz thermodilution catheter (Edwards Lab, Santa Ana, CA, USA) advanced into a pulmonary artery. The mean value was used. The variability of the measurements was less than $5 \%$. The gradient between wedged and free hepatic venous pressures (hepatic venous pressure gradient) was then measured with a $7 \mathrm{~F}$ catheter (Cordis SA, Miamia, FL, USA) introduced into the right hepatic vein under fluoroscopic control. The wedged position of the catheter was checked by the absence of reflux after injection of $2 \mathrm{ml}$ contrast medium into the catheter. The free hepatic venous pressure was measured in the right hepatic vein just before its junction with the inferior vena cava. Right atrial pressure was measured before withdrawing the catheter. The zero reference level was arbitrarily positioned at the midaxillary line level. Systemic vascular resistance (dynes $\mathrm{s} \mathrm{cm}^{-5}$ ) was calculated according to the following formula: (mean arterial pressure $(\mathrm{mmHg})$ - right atrial pressure $(\mathrm{mmHg}))$ $.80 /$ cardiac output ( $1 / \mathrm{min})$. Azygos blood flow was measured by the local continuous thermodilution method using a digital electronic computer (Calculateur de débit, AHS/France, Saint Ouenl'Aumône, France), as previously described." 10 In brief, a continuous-thermodilution catheter (Webster Lab, Altadena, CA, USA) with a curved tip was introduced into the arch of the azygos vein up to $5 \mathrm{~cm}$ from its junction with the superior vena cava, under fluoroscopic control; its position was checked by injection of contrast medium into the catheter. The continuous-thermodilution catheter was then fixed to the polypropylene sheath (so as to be able to repeat azygos blood flow measurements with the catheter tip being at the same level in the lumen of the azygos vein). The mean of six determinations of azygos blood flow was used (variability less than $7 \%{ }^{10}$ ).

The results are expressed as mean $\pm \mathrm{SD}$. Analysis 
Table 2 Haemodynamic data in patients with cirrhosis according to the degree of liver failure*

\begin{tabular}{|c|c|c|c|}
\hline & Group $A$ & Group B & Group C \\
\hline Patients (n) & 16 & 18 & 16 \\
\hline Mean arterial pressure $(\mathrm{mmHg})$ & $87 \cdot 6 \pm 15 \cdot 5 \div$ & $86 \cdot 7 \pm 9 \cdot 6$ & 8()$\cdot 3 \pm 11 \cdot 7$ \\
\hline Heart rate (beats $/ \mathrm{min}$ ) & $74 \cdot() \pm 13 \cdot()$ & $86 \cdot 5 \pm 12 \cdot()+$ & $95 \cdot 7 \pm 12 \cdot 4 \S$ \\
\hline Cardiac index $\left(1 \cdot \mathrm{min}^{-1} \cdot \mathrm{m}^{-2}\right)$ & $3 \cdot 49 \pm(0 \cdot 51$ & $4 \cdot(0) \pm 1 \cdot(08$ & $4 \cdot 68 \pm 1 \cdot 64$ \\
\hline Systemic vascular resistance $\left(\right.$ dyne $\left.\cdot s \cdot \mathrm{cm}^{-5}\right)$ & $1252 \pm 419$ & $1085 \pm 341$ & $951 \pm 3(07$ \\
\hline Wedged hepatic venous pressure (mmHg) & $26 \cdot 1 \pm 4 \cdot 9$ & 3()$\cdot 4 \pm 7 \cdot 7$ & $32 \cdot() \pm 6 \cdot() \$$ \\
\hline Free hepatic venous pressure $(\mathrm{mmHg})$ & $8 \cdot 3 \pm 2 \cdot 6$ & $8 \cdot 7 \pm 4 \cdot 8$ & $8 \cdot 8 \pm 3 \cdot 5$ \\
\hline Hepatic venous pressure gradicnt $(\mathrm{mmHg})$ & $17 \cdot 8 \pm 5 \cdot 6$ & $21 \cdot 7 \pm 7 \cdot()$ & $23 \cdot 3 \pm 7 \cdot 4$ \\
\hline Azygos blood flow ( $1 / \mathrm{min})$ & $0.477 \pm(0.242$ & $(0 \cdot 642 \pm(0 \cdot 224$ & $1 \cdot(061 \pm(0.476 \$ 9$ \\
\hline Azygos blood flow/cardiac output $(\%)$ & $7 \cdot 6 \pm 3 \cdot 5$ & $10 \cdot 2 \pm 4 \cdot 4$ & $14.6 \pm 6.9$ \\
\hline
\end{tabular}

${ }^{*}$ According to a modified Pugh’s classification (sec Method section). $\doteqdot$ Mean \pm SD. $\doteqdot$ Significantly different from group $A(p<0) \cdot(01)$. $\S$ Significantly different from group A $(\mathrm{p}<0 \cdot()() 1)$. ||Significantly different from group A $(\mathrm{p}<() \cdot() 2)$. ISignificantly different from group B $(\mathrm{p}<0 \cdot 01)$

of variance and the Bonferoni method for multiple statistical comparison were used. Accordingly, results were considered significant only at $\mathrm{p}<0 \cdot 02$. Student's $t$ test for unpaired and paired data was used to compare the results among the different groups of patients and, within a group, the results before and after propranolol administration.

\section{Results}

BASELINE HAEMODYNAMICS ACCORDING TO THE DEGREE OF LIVER FAILURE

The results are presented in Table 2. There was no significant difference between the three groups of patients with regard to mean arterial pressure, free hepatic venous pressure, and systemic vascular resistance. There were, however, significant differences between the three groups with regard to heart rate, cardiac index, wedged hepatic venous pressure, azygos blood flow, and fractional distribution of cardiac index to azygos venous bed. Changes from normal were more marked in group $C$ patients than in groups A and B patients; statistically significant differences were only found between group $\mathrm{A}$ and group C.

\section{HAEMODYNAMIC EFFECTS OF PROPRANOLOL} ACCORDING TO THE DEGREE OF LIVER FAILURE The effects of propranolol according to the degree of liver failure were evaluated in 24 patients. The results are presented in Table 3. Propranolol significantly altered heart rate, cardiac output, and systemic vascular resistance in all three groups of patients. After propranolol, cardiac outputs were not significantly different between the three groups. Changes were proportionally greater in group $\mathrm{C}$ than in group $\mathrm{A}$; the differences between group $\mathrm{A}$ and group $B$ responses and between group $B$ and group $\mathrm{C}$ responses were not statistically significant.
Propranolol significantly decreased hepatic venous pressure gradient with similar proportional change in the three groups of patients. After propranolol administration, one patient in group $\mathrm{A}$, one patient in group $\mathrm{B}$, and two patients in group $\mathrm{C}$ showed no change in hepatic venous pressure gradient. Azygos blood flow was decreased in all patients except one in group $\mathrm{C}$; the magnitude of the decrease, however, was highly variable in group $\mathrm{C}$ patients while it was consistent in group A and B patients. After propranolol administration in group $\mathrm{C}$, mean azygos blood flow remained higher than baseline mean azygos blood flow in groups $\mathrm{A}$ and $\mathrm{B}$. The fractional distribution of cardiac output to azygos blood flow decreased after propranolol administration in groups $A$ and $B$ and increased in group C. A significant change was, however, observed only in group B.

\section{Discussion}

In agreement with several previous reports, this study documents a relationship between liver failure and the hyperkinetic circulatory state that is associated to cirrhosis. ${ }^{1-3}$ This study also shows a less well documented relationship between the degree of liver failure and the magnitude of the circulatory alterations in the splanchnic vascular bed.

Portal pressure and portal tributary blood flow are two major factors characterising splanchnic haemodynamics. The present findings indicate a weak relationship between liver function and wedged hepatic venous pressure - a reliable estimate of portal venous pressure in patients with cirrhosis. "12 Similarly, other workers have reported a correlation between hepatic venous pressure gradient and bilirubin or albumin serum level. ${ }^{13}$ Such a relationship is not surprising as deteriorating liver function may be expected to follow the progressive structural alterations that are 


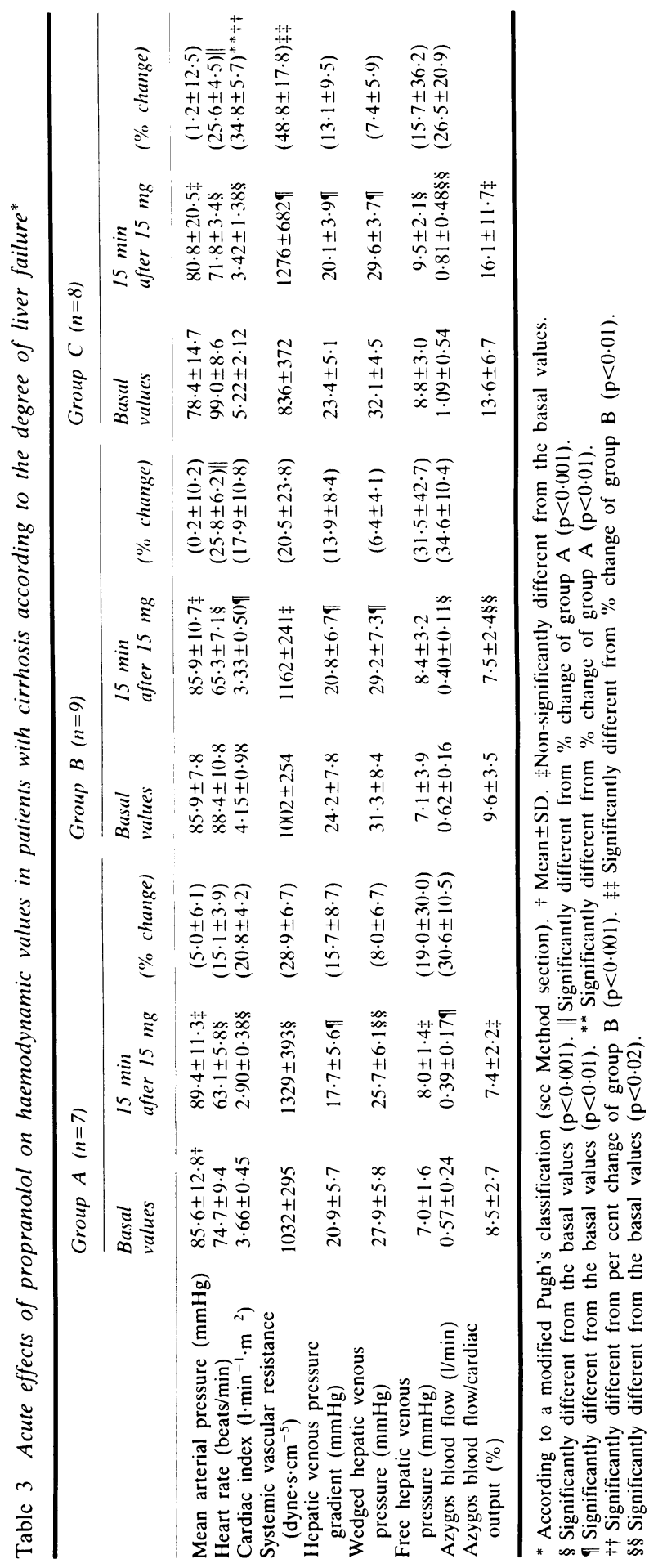


known to be related to portal venous pressure. ${ }^{14}$ The presence of ascites in patients of group $\mathrm{C}$ might also influence the interpretation of the results obtained. This mechanism is, however, unlikely because it has previously been shown that the effect of increased intraabdominal pressure has no effect on portal pressure (hepatic venous pressure gradient) in patients with cirrhosis. ${ }^{15}$

At the present time, portal tributary blood flow unfortunately cannot be easily measured in patients with cirrhosis. A part of portal tributary blood flow is shunted towards the systemic circulation through collateral veins, among which the superior ones are of utmost clinical importance because they include oesophageal varices. Most of the superior portosystemic collateral channels drain into the azygos vein; thus, azygos blood flow represents the sum of blood flow in the superior portosystemic collaterals and of blood flow in the lumbar, intercostal, and mediastinal veins. This latter part of the azygos blood flow amounts to approximately $100 \mathrm{ml} / \mathrm{min}$ in patients without portal hypertension and with normal cardiac output." 1015 lo It may reasonably be assumed that in patients with cirrhosis, owing to a $20-50 \%$ increase in cardiac output, this part of azygos blood flow should be increased to approximately $120-150 \mathrm{ml} / \mathrm{min}$. The increase in azygos blood flow observed in patients with cirrhosis does not directly depend on the increase in cardiac output as in patients with distal splenorenal shunt, azygos blood flow decreased whereas cardiac output, in general, increases. ${ }^{16}$ Accordingly, in this study, the part of azygos blood flow corresponding to the portosystemic collateral circulation was increased on average by $300 \mathrm{ml} / \mathrm{min}$ in group $\mathrm{A}$ but by $800 \mathrm{ml} / \mathrm{min}$ in group C patients. Thus, the high grade hyperkinetic state that characterises the systemic circulation in patients with advanced liver failure also affects the portosystemic collateral circulation. The increase in portosystemic collateral blood flow could be a mere consequence of the hyperdynamic circulatory state affecting equally portal venous tributary blood flow and other regional blood flows. Alternatively, it could result from a particular increase in portal tributary blood flow as compared with other regional blood flows. The latter hypothesis would be supported by the observations that (a) fractional distribution of cardiac output to the azygos venous bed was significantly increased in patients with advanced liver failure as compared with patients with no or moderate impairment in liver function and (b) rats with portal hypertension due to portal vein stenosis showed a disproportionately marked increase in portal tributary blood flow when compared to the simultaneous moderate increase in cardiac output. ${ }^{17-19}$ Significant differences in azygos blood flow according to the degree of liver failure have not recently been found in cirrhotic patients. ${ }^{20}$

The cause of the increasing changes in portal and systemic haemodynamics that are associated with progressively more severe impairment in liver function is not clearly known. Alterations in the metabolism of endogenous substances with circulatory actions are likely. The main substances which have been implicated include catecholamines, ${ }^{21}$ false neurotransmitters, ${ }^{22}$ substance $P,{ }^{2.3}$ vasoactive intestinal peptide. ${ }^{24}$ That adrenergic activation is an important determinant of the hyperdynamic state is indicated by the significant reduction obtained after $\beta$-adrenergic blockade with propranolol in all the groups of patients in this study. This observation is at variance with the results of a study in which hepatic venous pressure gradient was little reduced by propranolol in patients with advanced liver failure; in that study, though, azygos blood flow was measured." A recent paper, however, has shown similar results to our study. ${ }^{110}{ }^{25}$ On the other hand, the hyperdynamic syndrome affecting both the systemic circulation and the portosystemic collateral circulation might also be determined by factors unrelated to adrenergic activation because $\beta$ adrenergic blockade did not return haemodynamic values to normal especially in patients with advanced liver failure. Incidentally, it must be noted that the significant decreases in hepatic venous pressure gradient, azygos blood flow and cardiac output after intravenous administration of $15 \mathrm{mg}$ propranolol are similar to those recently reported in a group of unselected patients with cirrhosis but the decrease in hepatic venous pressure gradient and in cardiac output slightly differs from other previously reported investigations where $40 \mathrm{mg}$ or more of propranolol were administered per os $;^{2526}$ the reason for this discrepancy is unclear but may be attributed, at least in part, to the route of administration of this $\beta$-blocker.

The respective importance of adrenergic and nonadrenergic factors in mediating the circulatory changes associated with cirrhosis might vary according to the degree of impairment in liver function. For example, the fractional distribution of cardiac output to the azygos venous bed was significantly decreased after propranolol only in patients with good or moderately impaired liver function. In other words, in spite of a marked decrease in azygos blood flow in patients of group $C$, the value of azygos blood in this group remained higher than in groups $A$ and B whereas the values for cardiac output in patients of the three groups became similar after propranolol administration. Thus, in view of the present findings, careful stratification according to 
the degree of liver failure, is warranted in any study on drugs acting on the circulation in cirrhosis.

Drs A Braillon and D Valla hold fellowships from the Fondation pour la Recherche Médicale. This work was presented in part (poster) at the 35th Annual Meeting of the American Association for the Study of Liver Diseases in Chicago on 10-11 November 1984 and published in abstract form (Hepatology 1984; 4: 1026). The authors thank Ms C Bertin and $M$ Naudet for assistance and Dr C Dupont from ICI Pharma-France for her help.

\section{References}

1 Kowalski HJ, Abelman WH. The cardiac output at rest in Laennec's cirrhosis. J Clin Invest 1953; 32: 1(225-33.

2 Siegel JH, Goldwyn RM, Farrel EJ, Gallin P, Friedman HP. Hyperdynamic states and the physiologic determinants of survival in patients with cirrhosis and portal hypertension. Arch Surg 1974; 108: 282-92.

3 Valla D, Poynard T, Bercoff E, Bataille C, Goldfarb G, Lebrec D. Le syndrome d'hypercinésie circulatoire systémique chez les malades atteints de cirrhose. Relation avec l'insuffisance hépatocellulaire et l'hypertension portale. Gastroenterol Clin Biol 1984; 8: 321-4.

4 Lebrec D, Bataille C, Bercoff E, Valla D. Hemodynamic changes in patients with portal venous obstruction. Hepatology 1983; 3: 550-3.

5 Nespoli A, Bevilacqua G, Staudacher C, Rossi N, Salerno F, Castelli MR. Pathogenesis of hepatic encephalopathy and hyperdynamic syndrome in cirrhosis. Role of false neurotransmitters. Arch Surg 1981; 116: 1129-38.

6 Colman JC, Jennings GL, McLean AJ, Mignot PR, Dudley FJ. Propranolol in decompensated alcoholic cirrhosis. Lancet 1982; 2: 1040-1.

7 Pugh RNH, Murray-Lyon IM. Dawson JL, Pietroni MC, Williams R. Transection of the oesophagus for bleeding oesophageal varices. Br J Surg 1973; 60: 646-9.

8 Lebrec D, Goldfarb G, Degott C, Rueff B, Benhamou JP. Transvenous liver biopsy. An experience based on 1000 hepatic tissue samplings with this procedure. Gastroenterology 1982; 83: 338-40.

9 Braillon A, Calès P, Jiron MI, Lebrec D. Estimation du débit sanguin des anastomoses porto-caves supérieures par la mesure du débit sanguin azygos chez les malades atteints de cirrhose alcoolique. Gastroenterol Clin Biol 1984; 8: 47-51.

10 Calès P, Braillon A, Jiron MI, Lebrec D. Superior portosystemic collateral circulation estimated by azygos blood flow in patients with cirrhosis. Lack of correlation with oesophageal varices and gastrointestinal bleeding. Effect of propranolol. J Hepatol 1984; 1: 37-46.

11 Boyer TD, Triger DR, Horisawa M, Redeker AG, Reynolds TB. Direct transhepatic measurement of portal vein pressure using a thin needle. Comparison with wedged hepatic vein pressure. Gastroenterology 1977; 72: 584-9.
12 Valla D, Bercoff E, Menu Y, Bataille C, Lebrec D. Discrepancy between wedged hepatic venous pressure and portal venous pressure after acute propranolol administration in patients with alcoholic cirrhosis. Gastroenterology 1984; 86: 1400-3.

13 Leevy CM, Zinke M, Baber J, Chey WY. Observations on the influence of medical therapy on portal hypertension in hepatic cirrhosis. Ann Intern Med 1958; 49: 837-51.

14 Poynard T, Degott C, Munoz C, Lebrec D. Acute alcoholic hepatitis and portal hypertension in patients with cirrhosis [Abstract]. Hepatology 1982; 2: 676.

15 Iwatsuki S, Reynolds TB. Effect of increased intraabdominal pressure on hepatic hemodynamics in patients with chronic liver disease and portal hypertension. Gastroenterology 1973; 65: 294-9.

16 Bosch J, Groszmann RJ. Measurement of azygos venous blood flow by a continuous thermal dilution technique: an index of blood flow through gastroesophageal collaterals in cirrhosis. Hepatology 1984; 4: $84-9$.

17 Blanchet L, Lebrec D. Changes in splanchnic blood flow in portal hypertensive rats. Eur J Clin Invest 1982; 12: 327-30.

18 Lebrec D, Blanchet L. Effect of two models of portal hypertension on splanchnic organ blood flow in the rat. Clin Sci 1985; 68: 23-8.

19 Vorobioff J, Bredfeldt JE, Groszmann RJ. Hyperdynamic circulation in portal-hypertensive rat model: a primary factor for maintenance of chronic portal hypertension. Am J Physiol 1983; 244: G52-7.

20) Bosch J, Mastai R, Kravetz D, Bruix J, Rigau J, Rodés J. Measurement of azygos venous blood flow in the evaluation of portal hypertension in patients with cirrhosis. Clinical and haemodynamic correlations in 100 patients. J Hepatol 1985; 1: 125-39.

21 Henriksen JH, Christensen NJ, Ring-Larsen H. Noradrenaline and adrenaline concentrations in various vascular beds in patients with cirrhosis. Relation to haemodynamics. Clin Physiol 1981; 1: 283-304.

22 Bernardi M, Trevisani F, Santini C, Zoli G, Baraldini M, Ligabue A, Gasbarrini G. Plasma norepinephrine, weak neurotransmitters, and renin activity during active tilting in liver cirrhosis: relationship with cardiovascular homeostasis and renal function. Hepatology 1983; 3: 56-64.

23 Hörtnagl H, Singer EA, Lenz K, Kleinberger G, Lochs $H$. Substance $P$ is markedly increased in plasma of patients with hepatic coma. Lancet 1984; 1: 480-3.

24 Hunt S, Vaamonde CA, Rattassi T, Berian G, Said SI, Papper S. Circulating levels of vasoactive intestinal polypeptide in liver disease. Arch Intern Med 1979; 139: 994-6.

25 Bosch J, Mastai R, Kravetz D, et al. Effects of propranolol on azygos blood flow and hepatic and systemic hemodynamics in cirrhosis. Hepatology 1984; 6: $1200-5$.

26 Lebrec D, Hillon P, Munoz C, Goldfarb G, Nouel O, Benhamou JP. The effect of propranolol on portal hypertension in patients with cirrhosis: a hemodynamic study. Hepatology 1982; 2: 523-7. 